\title{
EL ROL DE LA MEMORIA EN LA CONSTRUCCIÓN DEL SUJETO EN LA CUENTÍSTICA DE MARCIO VELOZ MAGGIOLO
}

\section{The role of memory in the construction of the subject in the short story of Marcio Veloz Maggiolo}

Fari Rosario $^{1}$

Recibido: 8-6-2016 • Aprobado: 29-9-2016

-Sócrates: "Pues bien, digamos que es un don de Memoria, la madre de las Musas: aquello de que queremos acordarnos de entre lo que vimos, oimos o pensamos, lo imprimimos en este bloque como si imprimiéramos un cuño de un anillo"

(Platón, Teeteto, 191d)

\section{Resumen}

Este artículo académico responde a la pregunta qué significado tiene la memoria en la construcción del sujeto en la cuentística del escritor dominicano Veloz Maggiolo. Desde la perspectiva del análisis del discurso —que valora, en esencia, el discurso como un proceso de construcción de conocimiento - se analizan seis cuentos representativos de dicho autor. En este trabajo se defiende la idea de que la exploración de la memoria es el fundamento de construcción del sujeto en los cuentos del escritor mencionado más arriba. De modo que el sujeto no se configura mediante acciones fácticas, sino mediante la memoria como eje de tensión y comprensión del mundo. El estudio ha sido posible en virtud de un modelo que describe y evalúa, de modo sistemático, elementos discursivos y estructurales en cada uno de los cuentos analizados. Se concluye que la memoria no solo construye y configura la subjetividad del sujeto (individual y colectivo), sino que se constituye en un elemento prototípico de la cuentística de Veloz Maggiolo. Por tanto, la memoria tiene una función onírica, textual e intertextual.

Palabras clave: memoria; análisis del discurso; construcción del sujeto; Veloz Maggiolo; referencia prototípica.

1. Profesor del INTEC. Correo electrónico: ramon.rosario@ intec.edu.do

\begin{abstract}
This academic article answers the question what meaning has the memory in the construction of the subject in the Dominican short story of the writer Veloz Maggiolo. From the perspective of discourse analysis which assesses, in essence, the speech as a knowledge-building process, six representative stories of the author are analyzed. This paper defends the idea that the exploration of memory is the basis for construction of the subject in the stories of the writer mentioned above. So the subject is not configured by factual actions, but by the memory as the axis of tension and understanding of the world. The study was made possible under a model that describes and evaluates, systematically, discursive and structural elements in each of the stories analyzed. We conclude that memory not only builds and configures the subjectivity of the subject (individual and collective), but constitutes a prototypical element of the short story of Veloz Maggiolo. Therefore, the memory has a dream, textual and intertextual function.
\end{abstract}

Keywords: memory; narrative construction of the subject; Veloz Maggiolo; prototypical reference. 


\section{Introducción}

Noam Chomsky (2007) es quien sitúa el estudio del lenguaje a nivel de la oración o la proposición, pues construye un modelo matemático-hipotético que permite describir el nivel superficial y profundo de las oraciones de cualquier lengua natural. A partir de la década de 1970, la lingüística toma un nuevo giro al postular el texto como objeto real de estudio; esta singular corriente es la que se denomina lingüística del texto. Pero no se estudia el texto concebido como un montón de palabras juntas, o como suma de signos, sino como objeto semiótico ${ }^{2}$, donde nace el sentido y las grandes prácticas sociales.

En el contexto antes descrito surge el análisis del discurso en la década de los ochenta a la par con el Análisis Crítico del Discurso (ACD). Ambas corrientes postulan que el discurso es el terreno ideal donde deben estudiarse la ideología, el poder y la discriminación racial como categorías importantes para la comprensión interdisciplinar de las ciencias sociales y su devenir. El ACD hoy por hoy es una fuerte corriente europea de la lingüística postmoderna que está encabezada por Ruth Wodak, Van Dijk y Norman Fairclough, Meyer, entre otros.

Este tipo de análisis es un modo de construir el conocimiento, de comprender, de un modo crítico y plausible, grandes fenómenos sociales y humanos. No solo es una teoría disciplinar, sino también una metodología científica, por lo que se encarga de estudiar una importante variedad de de discursos, tales como el discurso histórico, el político, el publicitario, el discurso de las élites del poder, así como lo relacionado con la construcción del discurso de las instituciones (en especial el discurso

\footnotetext{
2. "No es una suma de signos la que produce el sentido, sino el funcionamiento textual (Benveniste, 1977, pp. 67-68); idea esta que ha llevado a sostener al último Barthes, al último Derrida y a Kristeva, entre otros, que los textos son el lugar donde el sentido se produce y produce práctica significante". (Peña Abril, 1997, p. 16)
}

educativo) y el discurso literario. El discurso, de acuerdo con Roa Ogando (2016, p. 27), hay que entenderlo "como un proceso de constantes cambios y transformaciones multifactoriales, así como las teorías que permiten entender el discurso como producto o texto".

El punto de partida de este estudio es la pregunta ¿qué significado tiene la memoria en la construcción del sujeto en la cuentística de Veloz Maggiolo? Para el análisis del discurso literario que se propone aquí tomo seis cuentos del autor en cuestión, que son los siguientes: "La fértil agonía del amor", "La pierna de M. Lavalette", ambos cuentos del libro titulado $L a$ fértil agonía del amor (1982); los cuentos "El sueño de Simbad" y "La sombra de las tilapias", tomados del libro Cuentos, recuentos y casicuentos (1986) y los cuentos "Elvirita" y "La muerte del teniente Soler" del libro Palabras de ida y vuelta (2006).

Vale acotar que son cuentos logrados, con una estructura narrativa densa y un tratamiento formal equilibrado y adecuado, ya que Veloz Maggiolo es un cuentista que maneja el oficio de narrar con maestría y esmero. Lo cierto es que ningún escritor dominicano ha explorado la memoria como este autor, quien ha tenido la osadía de llevar el tema al más alto nivel de expresión y complejidad conceptuales.

En este trabajo defiendo la idea de que la exploración de la memoria es el fundamento de la construcción del sujeto en los cuentos de Veloz Maggiolo. De modo que el sujeto no se configura mediante acciones fácticas, sino mediante la memoria como eje de tensión y comprensión del mundo. La memoria, más que un recurso registra o evoca el pasado, se muestra como un arquetipo atávico que hace posible la vinculación con el cuerpo y los escenarios simbólicos del mundo.

La premisa es que todo texto literario contiene las marcas contextuales de una época; se parte de la hipótesis de que esas marcas discursivas y semánticas filtran las ideologías y la cosmovisión del sujeto que enuncia y enfoca la realidad de 
un modo integral y total. En la construcción del sujeto según lo mostrado en los cuentos analizados, se evidencian dos aspectos medulares de la problemática:

1) cómo se construye el sujeto histórico (su subjetividad, sus miedos e ideas del mundo)

2) las sombras y los conflictos del sujeto virtual (entiéndase sociedad dominicana) a quien está destinado el discurso literario del autor analizado.

\section{Justificación de la indagación}

Se dice que el pueblo dominicano olvida fácil; que "el pueblo que olvida repite su historia". Resulta pertinente, pues, situar el concepto de memoria más allá de la perspectiva disciplinar que concierne a la Sociología o la Historia. Es necesario analizar el concepto también desde el seno de la literatura y desde el análisis discursivo entendido como un corpus de textos narrativos. De modo que es muy importante analizar la naturaleza e implicaciones semánticas de la memoria como recurso de construcción de los sujetos y de su conocimiento del mundo.

Esta introducción, aunque larga, es necesaria para lograr una mayor comprensión de lo que se planteará en el análisis posterior de los cuentos de Veloz Maggiolo, desde la perspectiva del análisis del discurso literario o artístico. Esta investigación es significativa porque aborda conceptos y elementos importantes no solo para estudiar el discurso literario, sino también para redefinir ciertos elementos curriculares relacionados con la interacción, la socialización y la educación de los sujetos en el siglo XXI.

Para la realización del trabajo se asumió la metodología hermenéutica o exégesis textual; el estudio tiene un enfoque netamente cualitativo y las unidades de análisis (los seis textos) se eligieron a conveniencia.

\section{Antecedentes de la investigación}

En el año 2002, Nina Bruni publica en México un trabajo sobre "el trujillismo en Uña y carne", de Marcio Veloz Maggiolo. Su estudio tiene como punto de partida la descripción de un corpus de cinco novelas dominicanas que abordan el tema de Trujillo. La autora elige Uña y carne, por su lenguaje sugerente y su alta complejidad formal, cualidades que la postulan como la novela de la construcción y la manipulación de la memoria y los olvidos. En resumen, el estudio plantea que la narrativa dominicana de las últimas décadas se desarrolla en torno al trujillato. Afirma que Uña y carne: memorias de la virilidad de Veloz Maggiolo aborda el tema de modo muy singular, destacando que:

La clave de acceso propuesta por Maggiolo es la memoria como resultado del pasado que retorna inexorable para develar la matriz perversa que el trujillismo ha dejado como herencia y que, aún hoy, moldea a la sociedad dominicana. Lo subjetivo conjugado con el lenguaje y la cultura locales del barrio de Villa Francisca, eje del relato, nos ofrece en el recuerdo de los personajes la perspectiva silenciada por la tiranía" (2002, p.153).

El investigador dominicano Rafael RodríguezHenríquez (2010) en su tesis doctoral abordó las fuentes de la imaginación histórica en la narrativa de Veloz Maggiolo. De su exploración conceptual se desprende un concepto capital y subrayado por este autor: "memoria imaginativa". El libro de Rodríguez-Henríquez analiza varias novelas de Veloz Maggiolo, tales como Materia prima y la novela Uña y carne: memorias de la virilidad, indagando sobre "la marcada presencia de la memoria, empleada en estas novelas para (re)crear el pasado" (p. 21) e interrogándose acerca de "¿cuál es la relación (o diferencia) entre mentir, imaginar y olvidar?” (p. 26). A través del análisis de la escritura etnográfica de dos novelas: El hombre del acordeón y La mosca 
soldado defiende la tesis de que el novelista [Veloz Maggiolo] crea "mundos mágico-maravillosos que expresan, al mismo tiempo, la auténtica idiosincrasia del pueblo dominicano" (p. 85).

Rodríguez Henríquez también analiza la "referencialidad histórica, veracidad e imaginación”, a través de las manifestaciones intertextuales presentes en las novelas, con el propósito de determinar "en el sentido más literal posible [...] la veracidad histórica de varias referencias ofrecidas, atendiendo a los factores que intervienen en la construcción de esas fuentes, tales como la imaginación, el olvido, y más importante aún, la confluencia de 'textos' asociados con los discursos literarios” (2010, p. 108).

\section{Fundamentación teórica}

El discurso es un macroacto, una unidad superior de análisis conformada de signos, símbolos, relaciones significantes, de prácticas sociales y pragmáticas. Es un campo abierto a la significación y la construcción del sentido. Y lo será más si el texto objeto de estudio es de carácter artístico o de factura estética. A continuación, se presenta una serie de enunciados en torno al discurso como concepto nodal, ya que es el eje donde se construye el sujeto y las grandes prácticas sociales y culturales.

Según Greimas (1971), el discurso es el lugar de construcción de un sujeto. Solo a través del discurso el sujeto construye el mundo como objeto y se construye a sí mismo mediante diversos actos de habla.

De acuerdo con Wodak, el análisis crítico del discurso no se centra en textos, hablados o escritos, sino que también hace énfasis en "la teorización y la descripción tanto de los procesos y la estructura sociales que dan lugar a la producción como de las estructuras sociales y los procesos en los cuales los individuos o los grupos, en tanto que sujetos históricos, crean sentidos en su interacción con textos"
(Fairclough y Kress, 1993, citado por Wodak \& Meyer, 2003, p. 19).

Uno podría preguntarse, a medida que lee un texto o lo escucha: ¿Cómo los sujetos crean sentido en la producción de un texto y cómo se refleja en el mismo la estructura de la interacción social?

Varios estudios y expertos del análisis del discurso han mostrado un modelo coherente para la producción textual y la recepción de textos, esto ha sido posible gracias al desarrollo del modelo cognitivo del lenguaje y porque han redefinido conceptos claves de la psicología y la lingüística cognitiva, tales como "memoria episódica" y "memoria semántica o a largo plazo". El criterio básico, según Van Dijk, ha sido la escogencia de textos como unidades básicas de análisis y como modos factibles de conocer la interacción social. Al respecto, Wodak \& Meyer, (2003, p. 25) afirman:

Los primeros trabajos de lingüística textual y análisis del discurso de Van Dijk (1977, 1981) muestran ya el interés que siente por los textos y los discursos y los discursos comprendidos como unidades básicas y como prácticas sociales. $\mathrm{Al}$ igual que otros teóricos de la lingüística crítica, Van Dijk busca los orígenes del interés lingüístico en unidades del lenguaje mayores que las proposiciones, así como en la dependencia que tienen los signos modificados respecto al texto y el contexto. Van Dijk y Kintsch (1983) han estudiado la relevancia del discurso para el estudio del procesamiento del lenguaje. Han desarrollado un modelo cognitivo de la comprensión del discurso de los individuos, y lo han hecho evolucionar gradualmente hasta convertirlo en varios modelos cognitivos que explican la construcción del significado en el plano societal.

De modo que el análisis del discurso atiende a los signos y los significados que se producen en las 
prácticas sociales y discursivas, pero también estudia la interdiscursividad, lo que es importante para describir el flujo de los supuestos, de la subjetividad y de la memoria en la acción cotidiana de los sujetos.

Esta investigación favorece el análisis hermenéutico de los seis cuentos seleccionados de Veloz Maggiolo, lo cual es coherente con la naturaleza y la metodología del Análisis Crítico del Discurso (ACD). Según Woldak \& Meyer (2003, p. 38), "por regla general, el ACD considera que su procedimiento es un proceso hermenéutico (...), la hermenéutica puede comprenderse como un método para aprehender y producir relaciones significativas". A sabiendas de que existen algunas diferencias marcadas entre el análisis del discurso y el ACD.

El análisis del discurso puede aplicarse a cualquier manifestación verbal (oral o escrita) o a cualquier corpus previamente elegido o construido, mientras que el segundo (el ACD), en palabras de Van Dijk "es un tipo de investigación analítica sobre el discurso que estudia primariamente el modo en que el abuso del poder social, el dominio y la desigualdad son practicados, reproducidos, y ocasionalmente combatidos, por los textos y el habla en el contexto social y político. El análisis crítico del discurso (...) toma explícitamente partido, y espera contribuir de manera efectiva, a la resistencia contra la desigualdad social" (Van Dijk, 1999, p. 2). Además, el ACD -por necesidad-implica asumir un enfoque inter y multidisciplinario, no así el análisis del discurso. Solo trato de plantear y de justificar que es válido utilizar la metodología hermenéutica del ACD en el análisis discursivo de cualquier corpus textual.

No basta con delimitar y esclarecer los conceptos que sostienen esta investigación; ahora es preciso asumir un procedimiento metodológico que haga posible la operacionalización de algunas unidades del análisis del discurso narrativo. Para materializar lo dicho en el enunciado anterior apelaré a dos conceptos: dispositivos contextuales y planos discursivos (Jäger, citado en Woldak \& Meyer, 2003). A través de la relación de estos planos se describen los cinco elementos o categorías discursivas para abordar los cuentos de Veloz Maggiolo; más adelante volveré sobre el aspecto.

En plena década de los sesenta, Benveniste (1989) reconoce que el sujeto enuncia y reconoce los límites de su experiencia en su enunciación. Esto es relevante porque en cada acto de habla, en una conversación cotidiana o en la enunciación de una frase hay una voluntad de comunicar, de lograr algo a través del uso de la lengua. De ahí que la experiencia y la búsqueda del individuo solo sean posibles mediante el discurso y la acción. Es así como se manifiesta su voluntad, su talante ético y su capacidad de poner en marcha la memoria y el conocimiento adquirido de la lengua materna.

La memoria se articula al mito y al principio de la narratividad, como bien ha mostrado la hermenéutica simbólica del siglo xx. Para Ricoeur (2003), la memoria se presenta como un nivel de tensión entre dos dimensiones intrínsecas al ser humano: el tiempo y la narración. Aborda el concepto desde la fenomenología de Husserl y afirma que la memoria se asocia con el pasado, con "la realidad anterior, ya que la anterioridad constituye la manera temporal por excelencia de la "cosa recordada", de lo «recordado» en cuanto tal" (2003, p. 22). No puede confundirse el concepto con imaginación, que es la dirección "hacia lo fantástico, la ficción, lo irreal, lo posible, lo utópico" (2003, p. 22).

Se entiende, pues, que sin memoria no hay vínculo con el pasado, pero tampoco es posible describir la temporalidad del sujeto, de su acción y la narración de los acontecimientos. De modo que los límites de la comprensión suponen la memoria, ya que "no tenemos otro recurso, sobre la referencia al pasado. A la memoria se vincula una 
ambición, una pretensión, la de ser fiel al pasado" (2003, pp. 40-41).

Sin embargo, Ricoeur parece olvidar o no tomar en cuenta que la memoria selecciona qué recordar del pasado, que organiza las informaciones y las imágenes según el interés y las necesidades directas del individuo, y que la memoria también altera los recuerdos. De igual modo, los narradores y escritores (Unamuno, Lodge, Fuentes) con experiencia confirman que ante el deseo de recordar algo y no poder recordarlo o situarlo, la memoria también inventa ciertos recuerdos. Los expertos en lingüística cognitiva e inteligencia artificial afirman que la memoria humana se altera cada vez que el individuo incorpora un nuevo conocimiento o nuevas imágenes semánticas del mundo. ¿Es absurdo pensar que la memoria se fermenta?

La lingüística del texto reconoce que la producción textual está estrechamente articulada a la memoria y al movimiento de los modelos cognitivos y la percepción de la realidad. Según Van Dijk (1983), en la estructura de un texto pueden estudiarse el contexto y algunas categorías de la lingüística textual, tales como el estilo, la memoria semántica o cultural, las estrategias de argumentación, el estilo retórico, etc.

La memoria cumple varias funciones, según los actos cotidianos, se da como actualización cartográfica (v. g. se recuerda el lugar de la ciudad visitado). Vale apuntar algo importante: según Plett (citado por Navarro, 2004), la memoria desempeña un rol importante en la alfabetización, de modo que es un principio determinante en el proceso de civilización individual y colectiva, por tanto, está en la base social de la construcción y los procesos de socialización.

\section{Las unidades de análisis del discurso narrativo}

En todo análisis del discurso, se identifican unas unidades básicas y pertinentes para el análisis que debe ejecutarse. Por ejemplo, en el análisis del Diario de Colón, Matos Moquete (1999) describe las siguientes unidades:

- El pronombre personal "уо"

- Las secuencias narrativas del texto

- Analizar el sujeto empírico: quién lo dice

- El uso y conteo de los verbos más frecuentes.

Para el análisis de los cuentos seleccionados de los tres libros de Veloz Maggiolo ya mencionados, tomaremos en cuenta cinco elementos que se articulan según lo contextual y según la operación de los planos discursivos. Los tres elementos primeros son extraídos del modelo mixto de Jäger (citado por Wodak y Meyer, 2003); los dos restantes son una contribución mía (según lo mostrado en la tabla 1).

\section{Tabla 1. Elementos de análisis discursivo}

1. Las implicaciones e insinuaciones, que pueden haberse expresado tácitamente

2. Las referencias (que incluye el discurso de las ciencias), las cosas y los objetos

3. Los pormenores relacionados con fuentes del conocimiento

4. La relación con el pasado (ucronía)

5. La asociación onírica y su vínculo con la naturaleza 
Veloz Maggiolo es un escritor prolífico y versado; está considerado como el escritor vivo más relevante y el fundador del discurso narrativo moderno de República Dominicana. Nace en Santo Domingo en 1936. Es cuentista y novelista; arqueólogo y antropólogo de formación. Hombre de vasta cultura y de batallas espirituales y cosmogónicas. Se graduó en Técnicas de Arqueología por la Universidad de Madrid, en 1970, donde también recibió el doctorado de Historia de América con especialidad en Prehistoria.

En 1960 publica El buen ladrón, su primera novela. Le siguen Creonte y seis relatos (1961); Intus (1962); El prófugo (1962); Judas (1962); La vida no tiene nombre (1965); Los ángeles de hueso (1966); Cultura, teatro y relatos en Santo Domingo (1969); De abril en adelante (1975); De dónde vino la gente (1978); Sobre cultura y política cultural en la República Dominicana (1980); La biografía difusa de Sombra Castañeda (1981); La palabra reunida (1981); Novelas cortas (1981), La fértil agonia del amor (1982); Apearse de la máscara (1986); Florbella (1986); Poemas en ciernes y Retorno a la palabra (1986), Materia prima (1990); Ritos de cabaret (1992); El jefe iba descalzo (1993); Trujillo,
Villa Francisca y otros fantasmas (1996); El hombre del acordeón (2003); La mosca soldado (2004); Memoria tremens (2009). Esta es su producción literaria; ha publicado asimismo más de una docena de investigaciones científicas en el campo de la arqueología, la antropología y la historia.

Pero además de novelista consagrado y diestro, Veloz Maggiolo es un cuentista de primera, que maneja el oficio, como pocos escritores del Caribe. Para este análisis he seleccionado dos cuentos del libro La fértil agonía del amor (1982); dos cuentos del libro Cuentos, recuentos y casicuentos (1986) y dos de Palabras de ida y vuelta (2006). ${ }^{3}$ Del libro La fértil agonía del amor (1982) he seleccionado para el análisis los cuentos "La fértil agonía del amor" (el que da título al texto) y el cuento "La pierna de M. Lavalette".

Primer cuento: La fértil agonía del amor

3. ¿Cuál ha sido el criterio de selección? He seleccionado los cuentos del libro que, a mi entender, orillan lo trascendente y trabajan el realismo fantástico. Son textos donde existe una fuerte tensión entre la dimensión subjetiva del sujeto, el contexto social y la realidad socio-cultural.

\section{Tabla 2a}

\begin{tabular}{lcc}
\hline Implicaciones e insinuaciones & Las referencias & $\begin{array}{c}\text { Pormenores y fuentes de } \\
\text { conocimiento }\end{array}$
\end{tabular}

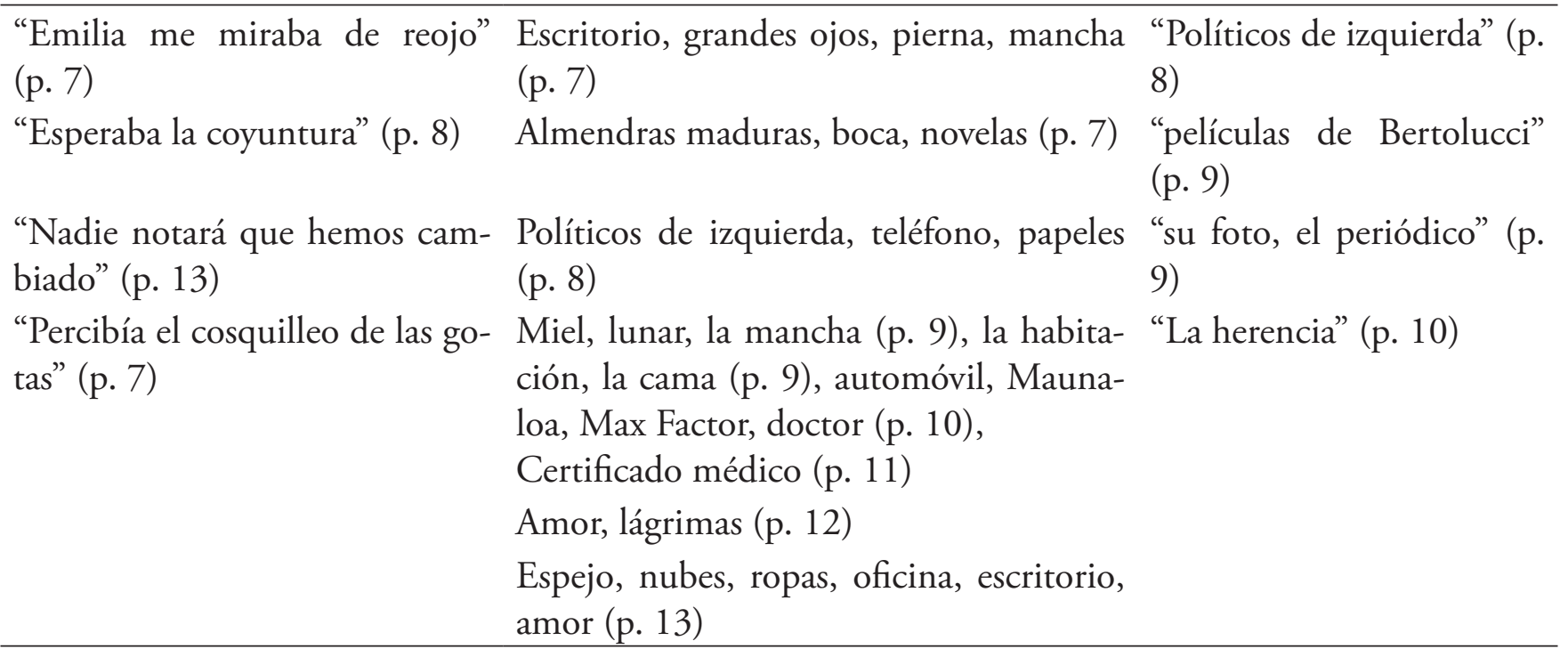


Tabla 2b.

\begin{tabular}{ll}
\hline \multicolumn{1}{c}{ Relación con el pasado (ucronía) } & La asociación onírica \\
\hline "Comparaba este amor con el de Odilia" (p. 9) & $\begin{array}{l}\text { "Sólo puedo tenerlo en sueños cuando reacciona mi } \\
\text { espíritu y lo veo posarse sobre mí" (p. 11) } \\
\text { "Sońé que me enamoraba de mí mismo" (p. 12) }\end{array}$ \\
"Aquella confusa sensación de ardor" (p. 12) & $\begin{array}{l}\text { "Pensé en ese momento en la pobreza de su ma- } \\
\text { trimonio" (p. } 7)\end{array}$
\end{tabular}

En este cuento, como podrá notarse, hay dos elementos predominantes: el elemento de las implicaciones y las insinuaciones (lo cual es cónsone con la atmósfera de la historia narrada y con la trama); el segundo se refiere a la contigüidad de las referencias (reales y semánticas). El segundo elemento también pone de manifiesto dos aspectos relevantes: el escritorio como imagen prototípica y marca de implicación de Gabriel como hombre importante, de negocios, educado y seductor. Eso, por un lado; por otro, muestra una mezcla de objetos reales a la vez que alude a sensaciones corpóreas ("llegaba en las mańanas con ese perfume como de palmeras en flor") y partes del cuerpo humano. La memoria se manifiesta a través de todos los elementos, pero en especial del primero (las insinuaciones) y también como conflicto de conciencia (asociación onírica). Pasemos al siguiente cuento.

Segundo cuento: La pierna de M. Lavalette

\section{Tabla 3a}

\begin{tabular}{|c|c|c|}
\hline Implicaciones e insinuaciones & Las referencias & $\begin{array}{l}\text { Pormenores y fuentes de } \\
\text { conocimiento }\end{array}$ \\
\hline "Nadie ha osado creerlo" (p. 61) & $\begin{array}{l}\text { La pierna, el jardín, Lavalette, autobús } \\
\text { (p. 62) }\end{array}$ & $\begin{array}{l}\text { "La India y sus tradiciones" } \\
\text { (p. 62) }\end{array}$ \\
\hline "Una historia espinosa" (p. 62) & $\begin{array}{l}\text { Hombre, madera, rosa musga (p. 62), } \\
\text { India, hotel }\end{array}$ & $\begin{array}{l}\text { "el lenguaje místico del per- } \\
\text { fume" (p. 67) }\end{array}$ \\
\hline \multirow[t]{6}{*}{$\begin{array}{l}\text { "No me engañes, hombre" } \\
\text { (p. 63) }\end{array}$} & Niños semi-desnudos, nariz (p. 64) & $\begin{array}{l}\text { "Todos se asombraron de } \\
\text { jardín" (p. 67) }\end{array}$ \\
\hline & Pierna de palo, cuerpo (p. 65) & \\
\hline & $\begin{array}{l}\text { Espinas, chorro de sangre verdiazul } \\
\text { (p. 65) }\end{array}$ & \\
\hline & $\begin{array}{l}\text { Doctor, dolor, clavícula izquierda, ce- } \\
\text { rebro (p. 66) }\end{array}$ & \\
\hline & Tierra blanda, florero (p. 66) & \\
\hline & $\begin{array}{l}\text { Un hombre con forma de bouquet, } \\
\text { polvo (p. } 66 \text { ) }\end{array}$ & \\
\hline
\end{tabular}


Tabla 3b.

Relación con el pasado (ucronía)

La asociación onírica

"Al fondo, como único recuerdo de aquel lu- "Lavalette sintió dos síntomas raros y disímiles: dugar antes hermoso, se levantaba un arbusto" rante las noches un perfume" (p. 66) (p. 67)

"Percibió un buen día sonidos de abejorros en el interior de su habitación larga y cerrada" (p. 66)

En este cuento fantástico predominan las referencias somáticas (el cuerpo, la sangre, la pierna, el cerebro) y los elementos asociados con las fuentes del conocimiento. Lavalette busca una singular pierna perfumada y en su búsqueda tiene una experiencia fantástica que lo hace sucumbir en los brazos del misterio y el silencio. La memoria del sujeto actúa como recurso que filtra y ordena las sensaciones del mundo. Son sensaciones olorosas y dolorosas.

Del libro Cuentos, recuentos y casicuentos (1986) he seleccionado dos cuentos para el análisis: "El sueño de Simbad" y "La sombra de las tilapias".

Primer cuento: El sueño de Simbad

\section{Tabla $4 a$}

\begin{tabular}{|c|c|c|}
\hline Implicaciones e insinuaciones & Las referencias & $\begin{array}{c}\text { Pormenores y fuentes de } \\
\text { conocimiento }\end{array}$ \\
\hline \multirow{7}{*}{$\begin{array}{l}\text { "el vendedor me miraba bajo la } \\
\text { creencia de que era yo un pobre } \\
\text { loco" (p. 42) } \\
\text { "ella me guiñó el ojo como di- } \\
\text { ciéndome "cómprame»" (p. 43) }\end{array}$} & $\begin{array}{l}\text { Alfombra mágica, Bagdad (p. } \\
41)\end{array}$ & "Las mil y una noches" (p. 41) \\
\hline & $\begin{array}{l}\text { Sabú, Lima, Singapur, Egipto, } \\
\text { tejido (p. } 41 \text { ) }\end{array}$ & "Universidad de Madrid” (p. 41) \\
\hline & Los Andes, zona andina (p. 42) & $\begin{array}{l}\text { "Un folleto con la frase siguiente: se- } \\
\text { gún una tradición muy antigua..." } \\
\text { (p. 45) }\end{array}$ \\
\hline & Vendedor, comprador (p. 42) & \\
\hline & $\begin{array}{l}\text { Danzarina desnuda, odalisca, } \\
\text { mis manos (p. } 43 \text { ) }\end{array}$ & \\
\hline & $\begin{array}{l}\text { Mis ojos, mi pie, peces platea- } \\
\text { dos (p. } 45)\end{array}$ & \\
\hline & Lámparas, ladrones (p. 46) & \\
\hline
\end{tabular}




\section{Tabla 4b.}

\begin{tabular}{ll}
\hline Relación con el pasado (ucronía) & La asociación onírica \\
\hline "Me venía a la mente la historia de califa Abdul [y su mujer] & "La alfombra me llamaba, no había du- \\
que solo hacía el amor con él cuando este se encontraba en el & das" (p. 44) \\
más profundo de los sueños" (p. 44) & \\
"El vendedor dijo: once coleccionistas de alfombras le habían & "Cerré los ojos en el momento y caminé \\
hecho una historia similar" (p. 45) & en sueños" (p. 45) \\
\hline
\end{tabular}

El cuento tiene un narrador autodiegético, es decir, la historia que cuenta el personaje es $s u$ historia en busca de la alfombra con una odalisca de mujer que vio en la cristalería de una tienda en Lima, Perú. La primera línea del cuento muestra al narrador como un sujeto de memoria, dicho de otro modo, la memoria es el fundamento de lo que se cuenta. Aquí se evidencia, de modo claro, que de todos los elementos descritos predominan los que aluden a fuentes de conocimiento. Aluden a eso que podríamos llamar memoria textual o semántica. Junto a este elemento aparece otro importante: la asociación onírica, que se muestra como telón de fondo de lo fantástico y como límite de la experiencia del sujeto que explora el mundo.
Pero surge algo relevante para la investigación: ¿por qué en los cuentos analizados hasta aquí predominan las referencias somáticas y antropológicas que se relacionan con el cuerpo humano (ojos, pies, las manos, la boca)? ¿Son semas contextuales, una constelación de sentidos (Greimas, 1971) o referentes prototípicos en la estructura narrativa de Veloz Maggioló? Volveré sobre este punto.

Segundo cuento: La sombra de las tilapias

\footnotetext{
4. Lo curioso es que esas referencias representativas del cuerpo humano también las encontramos en algunos títulos de novelas de este autor, por ejemplo: Uña y carne (1999); Los ángeles de huesos (1966); Memoria tremens (2009), entre otras.
}

\section{Tabla 5a}

\section{Implicaciones e insinuaciones}

"Jacobo no pensaba de la misma ma- José, mariposas (p. 47) nera" (p. 48)

"el pastor evangélico había predi- Cielo azul, camino, corazón, fiecho"... (p. 48)

"Antonio opinaba que deberían

"Debe ir detrás de sus mariposas, pensó” (p. 51)

\section{Las referencias}

bre, mirar hacia el catre vecino

(p. 47)

Jacobo y Juana, rostro quemado, mecedora, yuca, lluvia (p. 47)

Viejo lago, memoria (p. 48), ojos

legańosos, perros, mejillas calentu-

rientas (p. 48)

\section{Pormenores y fuentes de} conocimiento

Ninguna

34 | Ciencia y Sociedad 2017; 42 (1): 25-43 


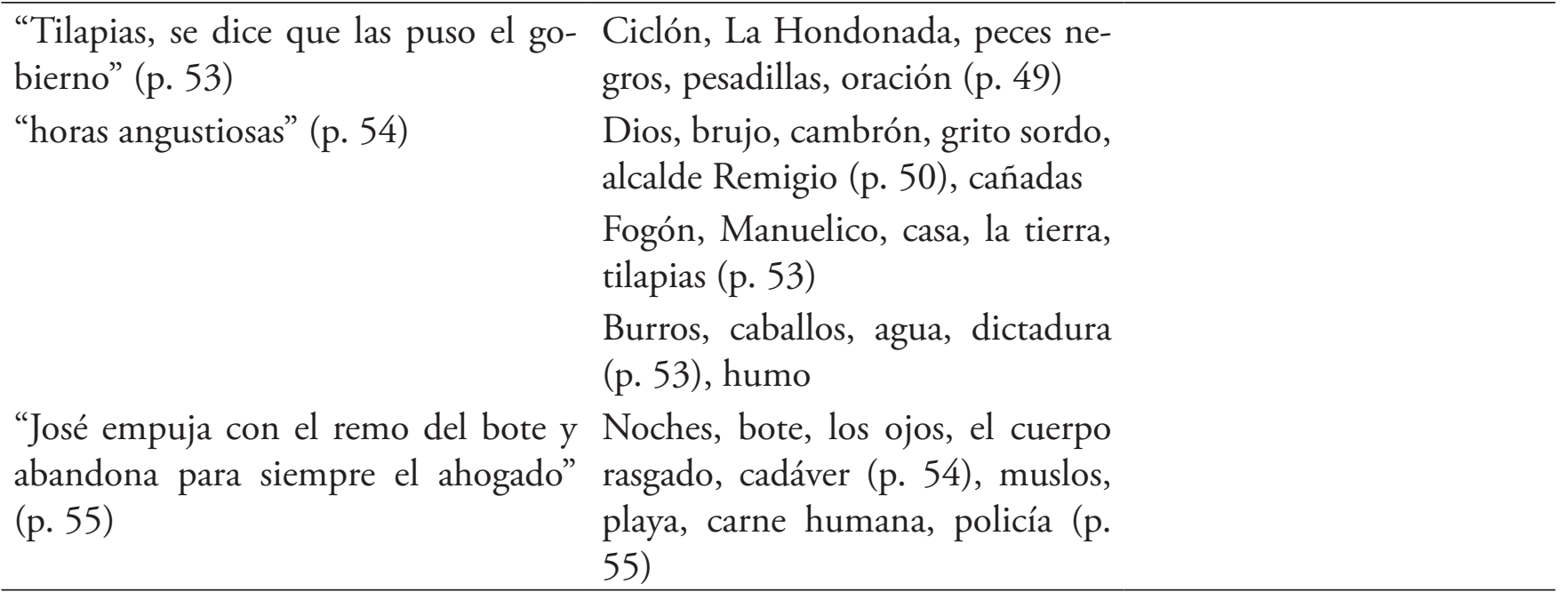

Tabla 5b

\begin{tabular}{|c|c|}
\hline Relación con el pasado (ucronía) & Asociación onírica y vínculo con la naturaleza \\
\hline "José caminaba tras su sueño" (p. 52) & $\begin{array}{l}\text { Desde hacía seis meses soñaba con mariposas" ( } p \text {. } \\
47 \text { ) }\end{array}$ \\
\hline \multirow[t]{4}{*}{ "José vuelve a pensar en las mariposas" (p. 55) } & $\begin{array}{l}\text { "José las veía en sueños: azules, grises, amarillas, ver- } \\
\text { des" (p. 48) }\end{array}$ \\
\hline & "José soñó esa noche” (p. 48) \\
\hline & $\begin{array}{l}\text { "Milenios de recuerdos resucitan no se sabe desde } \\
\text { dónde" (p. 52) }\end{array}$ \\
\hline & $\begin{array}{l}\text { "Quizás podrás entonces convencerlo de que es sue- } \\
\text { ño o locura" (p. 55) }\end{array}$ \\
\hline
\end{tabular}

Estamos ante un cuento estremecedor. Como es natural, predominan dos elementos referenciales: las mariposas y las tilapias. La carga de insinuaciones se mezcla y se redimensiona con el movimiento de las asociaciones oníricas y los delirios de la memoria. Aparece la memoria como vinculación atávica de la naturaleza y como instrumento de revelación de la muerte, del miedo, de las sombras de la conciencia y el sentimiento agónico y surreal que marca la existencia humana. Pero de nuevo, el cuerpo humano aparece como referencia o imagen prototípica en medio del resto de referencias naturales y cosas-objeto.

A continuación, analizamos los dos cuentos correspondientes al libro Palabras de ida y vuelta (2006). He seleccionado el cuento "Elvirita" y "La muerte del teniente Soler".

Primer cuento: Elvirita 


\section{Tabla 6a}

\section{Implicaciones e insinuaciones}

Las referencias

\section{Pormenores y fuentes de} conocimiento

"Elvirita, casi niña, destrozada Libro, Bécquer, ojos (p. 23), "Rima 71 de Bécquer" (p. 23) por la miseria de sus familiares" lienzo, mente, niña, miseria, (p. 23) manos, cadáver (p. 23), párpados, vudú, muerte, casa, armario, ropita, infarto (p. 23)

"Los muertos no quieren nada Tíos, luz, velón de parafina, ci- "Detuve mis ojos en los versos sicon el humo de cigarrillo" (p. garrillo, vestimenta, Boco Belié guientes” (p. 26) 24) (p. 24), cuerpos, cementerios, barrios pobres

"Quedan, señora, algunos paga- Cama, canapé sombrío, Her- "Entonces sigo leyendo: rés por cubrir" (p. 25) nando, funeraria (p. 25), deu- De la casa en hombros llevarónla al das, cura (sacerdote), espíritu templo, y en una capilla dejaron fére(p. 26) tro" (p. 25)

"Usted, no tiene derecho, debí Labios resecos, difuntos, borradecirle" (p. 25) cho, pecho, venganza (p. 26)

"Le dije que cómo se atrevía a Camposanto, nicho, manos de penetrar en un poema de Gusta- lirios, mis manos, poema, odio vo Adolfo Bécquer” (p. 27) intelectual (p. 27)

\section{Tabla 6b}

\section{Relación con el pasado (ucronía) Asociación onírica y vínculo con la naturaleza}

"Las deudas habían llevado a la muerte al padre y "Abrí el libro y volví a la rima: cerraron sus ojos que a la hija” (p. 26)

aún tenía abiertos" (p. 23)

"Y unos sollozando y otros en silencio" (p. 24)

“A dar a las ánimas el toque”... (p. 26)

“Dios mio, qué solos se quedan los muertos!”(p. 27)
En este cuento el elemento predominante, como se notará, corresponde a las insinuaciones e implicaciones (el primer elemento de la tabla 6a). También predominan las referencias al cuerpo humano y las referencias espirituales o culturales. Cabe destacar que la asociación onírica y metatextual es tan fuerte 
y significativa en este cuento que cumple una función narrativa y semiótica: comprende la muerte de la nińa Elvira a través de un poema. De modo que la memoria textual o semántica fundamenta el texto y lo organiza en fases cognitivas.

El sujeto de memoria, en el caso anterior, no solo construye la historia por evocación, sino que además construye la historia colectiva a través de la lectura de un poema clásico de la cultura española: la rima 71 del poeta Bécquer. Quizás el autor quiera dar una moraleja: Bécquer no es poeta muerto, sino el espejo temporal por el que puede leerse la miseria de muchos seres humanos y la de muchos barrios dominicanos.

Segundo cuento: La muerte del teniente Soler

\section{Tabla $7 \mathbf{a}$}

\section{$\begin{array}{lll}\text { Implicaciones e insinuaciones } \quad \text { Las referencias } & \text { Pormenores y fuentes de }\end{array}$ conocimiento}

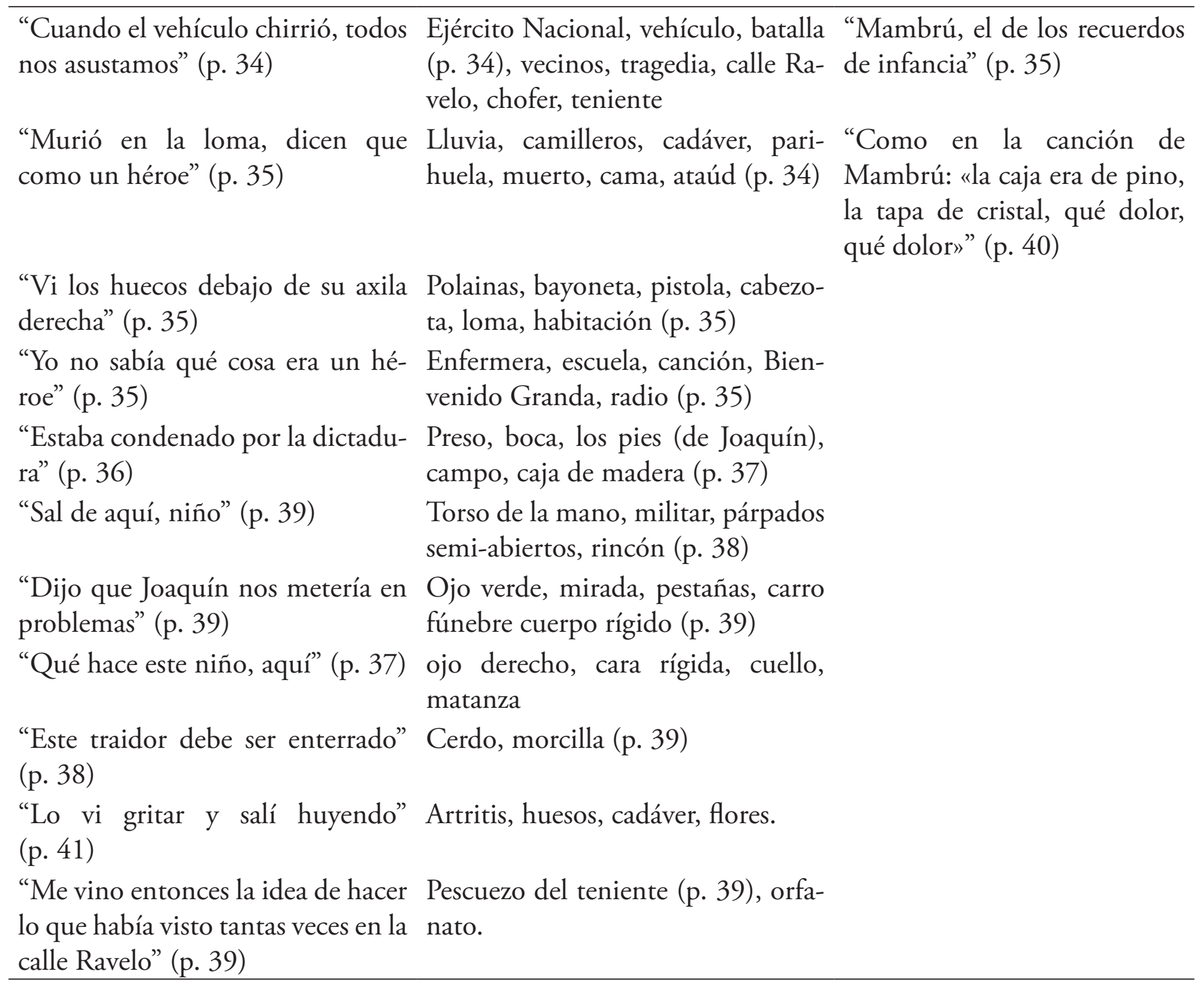


Tabla $7 \mathbf{b}$

Relación con el pasado (ucronía)

"Mis padres nunca regresaron y yo salí del orfanato seis años después" (p. 41)

\section{Asociación onírica y vínculo con la naturaleza}

"Me vino entonces la idea de hacer lo que había visto tantas veces en la calle Ravelo, en donde la matanza de cerdo era común” (p. 39)

"Si Joaquín me guiñaba el ojo era seguro que podía hacerlo" (p. 39)
Este es un cuento sumamente dramático y alucinante. Como se notará, en el plano textual y contextual de la narración predominan los elementos relacionados con las implicaciones y las insinuaciones. En ningún lugar se dice que Joaquín era un comunista; en realidad el lector tendrá que inferirlo según sus conocimientos del mundo; el que narra es el niño que asesinó al teniente Soler, pero que ya es un adulto, un sujeto maduro y con recuerdos confusos. Llama la atención, como en las secuencias o tablas anteriores, el entramado de las referencias, pues de nuevo encontramos vivas referencias al cuerpo humano (imagen semántica prototípica) junto a las referencias de cosas u objetos siniestros (bayoneta, pistola, p. 35).

El cuento es una analepsis, o sea, el recuerdo de un hombre de 65 años; en este cuento la memoria juega un rol hegemónico, pues se manifiesta como depósito de sombras, como el desalojo repentino de un fantasmario. Lo curioso y emblemático de esto es que Veloz Maggiolo es consciente de esto cuando afirma en el paratexto (prefacio) de uno de sus libros:

Un fantasmario es un depósito de fantasmas que ocupan parte del cerebro. Debería citar a Gustavo Adolfo Bécquer quien en sus obras habla de los tenebrosos rincones del cerebro donde «duermen acurrucados y desnudos los interminables hijos de mi fantasía». Si el cerebro tiene rincones tenebrosos, debe tener espacio suficiente para fantasmas, por eso no es de dudar que el fantasmario viva dentro de nosotros (Veloz Maggiolo, 2006, p. 10)

Es la memoria misma que emerge como fantasma inevitable e incorruptible.

De lo dicho y mostrado hasta aquí, pueden formularse dos ideas relevantes.

Primero: las insinuaciones y las implicaciones semánticas son estructuralmente representativas en todos los cuentos analizados. Este elemento quizá muestra el hilo de las represiones y los miedos que sienten los sujetos (dominicanos). Y esto es así, porque el sujeto que habla o narra en los cuentos está más próximo a las asociaciones oníricas que a las ucronías (vinculación con el pasado). De modo que esta memoria tejida de insinuaciones e implicaciones está en primer plano, mientras que las acciones (obtener una cita, obtener una pierna, matar un teniente, obtener una alfombra mágica) quedan en segundo plano. Por tanto, son acciones secundarias, casi pretextos para navegar en las profundas corrientes de la narración y el recuerdo.

Segundo: todas las referencias que aparecen en los cuentos analizados de Veloz Maggiolo podrían dividirse en dos: referencias prototipicas y referencias periféricas. ¿Cuáles son las prototípicas? ¿Por qué los cuentos se desarrollan como una oscilación semántica y simbólica entre ambas referencias? ¿Es el cuerpo humano una referencia prototípica en esta narrativa? Las referencias prototípicas son las 
somáticas: el cuerpo, la sangre, la pierna, el cerebro, la boca, los huesos, la memoria; mientras que las periféricas son las que se relacionan con el contexto, el conocimiento y lo histórico. Resumamos este asunto a través de dos gráficos:

\section{REFERENCIAS \\ PROTOTÍPICAS}

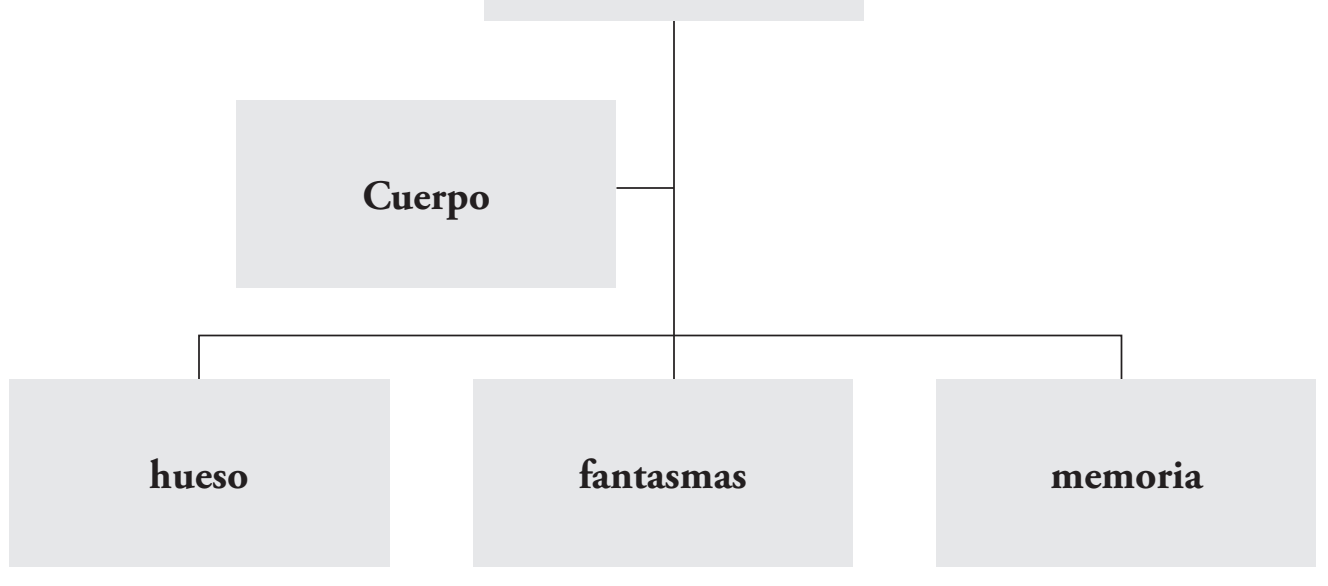

Fuente: elaboración propia.

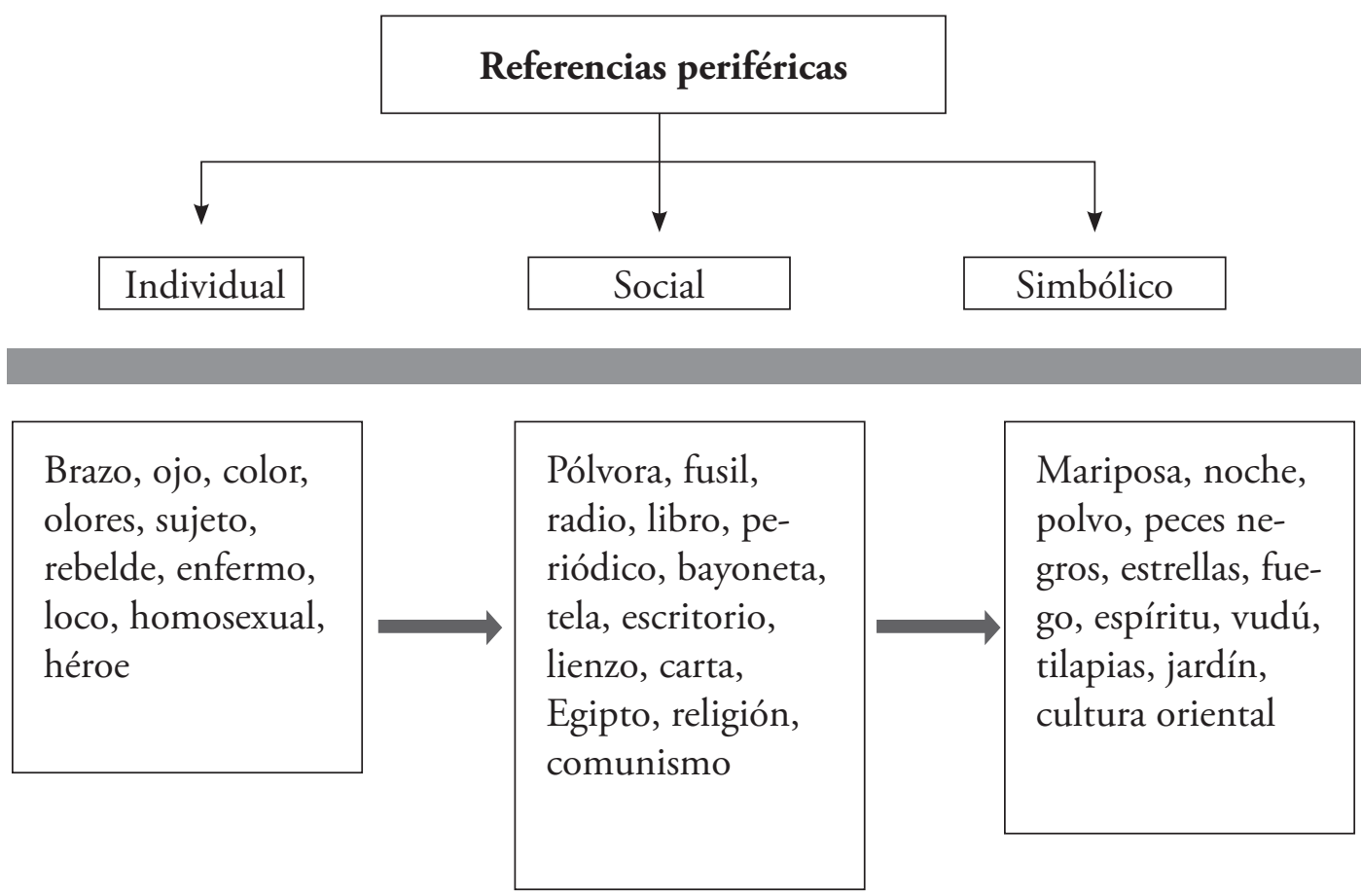

Fuente: elaboración propia. 
La memoria, en tanto que referente prototípico, es el denominador común de todos los cuentos analizados. Este elemento narrativo no solo construye el sujeto y su modo de relacionarse con las cosas y el mundo de la cotidianidad, sino que además unifica todos los actos de habla, los giros expresivos y las presuposiciones de la estructura ficcional. La transferencia de significación supone el movimiento continuo de la memoria ya sea como insinuación, ya sea como asociación, como recuerdo o bien como memoria textual.

La descripción de los cinco elementos discursivos pone de relieve que la memoria armoniza la estructura semántica de los cuentos, pero además facilita la construcción del sujeto a través de sus actos de habla, de las implicaciones o presuposiciones, según el contexto de la enunciación. La memoria está en el centro de toda evocación, de toda posible asociación onírica con los recuerdos, los deseos y los fantasmas de la cultura dominicana. La crítica especializada de República Dominicana al menos ha descrito, de soslayo, este aspecto, pues según Andrés L. Mateo: "La obra de Veloz Maggiolo es como un rollo chino, desenrollándose sin límites, gracias al cual esculpe parte de la vida espiritual de los dominicanos". (Véase la contracubierta de Memoria tremens, Alfaguara, 2009).

En ese mismo tenor de ideas, Fornerín afirma que Veloz Maggiolo "ha realizado un ejercicio literario con el firme propósito de que no se debe olvidar, así juega una política que se balancea en su propia estrategia. La memoria que es fragmento de recuerdo sólo es posible aprehenderla a través de aquellos elementos más lastimeros que permanecen como símbolos de un pasado traumático" (Fornerín, en Valerio-Holguín, 2000, p. 82, el énfasis es mío).

El sujeto de los cuentos analizados se caracteriza por ser aislado, reprimido, pasivo, un sujeto que no dialoga, sino que monologa con sus recuerdos.

En la manifestación de estos seis cuentos y su análisis semántico-discursivo se tejen, entre líneas, algunos matices que caracterizan el devenir del sujeto colectivo, sobre todo en lo que concierne al sujeto virtual, o sea, a quien se dirige el discurso literario. Todo discurso literario, como argumenta Greimas (1971), tiene un destinador y un destinatario. ¿Hay en estos cuentos una crítica a las ideologías que permean y perviven en el imaginario dominicano?

Contrario a la concepción lineal de la historia inaugurada por el cristianismo y la historia concebida como progreso, el discurso narrativo de Veloz Maggiolo sugiere que el sujeto solo se construye si mira hacia atrás, o al menos si quiebra la memoria de sus miedos y sus fantasmas más sombríos. Un discurso así es contrario al lema “borrón y cuenta nueva”. La cuenta jamás podrá ser nueva, ya que es la historia de una mancha social, de una huella que late y que duele.

\section{Conclusiones}

Los seis cuentos analizados del escritor dominicano Veloz Maggiolo muestran la memoria como un elemento prototípico, que no solo construye y muestra la subjetividad del sujeto (individual y colectivo), sino que funda su cuentística. La memoria no es un mero recurso para hurgar en la interioridad de los personajes o en los recovecos del pasado histórico, sino que implica una relectura del cuerpo humano, de las sensaciones, los olores, los colores, el olvido, la acción, la represión, el deseo de libertad y la dimensión simbólica de la conciencia.

Con lo dicho hasta aquí, se confirma la idea de Ricoeur (2003), quien sostiene que sin memoria no hay vínculo con el pasado, pero tampoco es posible describir la temporalidad del sujeto, su acción y su narración de los acontecimientos. Más que registrar momentos y experiencias, el significado de la memoria es hacer posible la comprensión del mundo y sus avatares familiares, sexuales, religiosos, políticos y ficticios. 
Se comprueba, pues, que en los cuentos de Veloz Maggiolo analizados, la evocación está en el núcleo de la constitución y la construcción del sujeto individual y colectivo. Algo relevante en la construcción del sujeto es que no solo construye la historia por evocación o insinuación, sino que además construye la historia colectiva de todo un pueblo, evalúa y esculpe la imagen de la vida espiritual y las costumbres mediante la memoria textual o semántica. De nuevo, esto confirma la tesis de Greimas (1971), de que el discurso es el lugar ideal para la construcción del sujeto. Pero también se recupera la tesis de Benveniste (1989, p. 28), de que "la lengua es el dominio del sentido". Y aún de algo más importante: en el lenguaje y en la enunciación encontramos los límites de la experiencia del sujeto que enuncia, pero también las marcas dignas de analizarse en su discurso. En cada acto de habla, en cada palabra dentro de un contexto de comunicación, en la conversación cotidiana o en la enunciación de una frase hay una voluntad de comunicar algo. Que no se olvide esto.

La importancia de este análisis del discurso de textos literarios no es solo poner en marcha el método hermenéutico y la descripción de los signos literarios, sino que hay otro factor importante: la integración de las unidades léxicas (palabras) con los enunciados o frases del discurso. La elección de los cinco elementos discursivos-narratológicos muestra la relevancia del aspecto metodológico para este estudio en particular, pero también su deseo de construir un modelo plausible de análisis discursivo que pueda, por igual, aplicarse a otros cuentos u otros autores dominicanos.

Con lo dicho hemos cumplido con los dos objetivos básicos y específicos de esta investigación. Con relación al primero, hemos analizado los aspectos y las marcas de la memoria en la construcción del sujeto que muestran los cuentos de Veloz Maggiolo. Para el segundo objetivo específico, que consistía en determinar qué función cumple la memoria en la construcción del sujeto individual y colectivo, se ha mostrado, con argumentos claros, que la memoria no es un recurso retórico, sino que cumple una función esencialmente prototípica en los cuentos de dicho autor. ${ }^{5}$

Del análisis realizado se desprenden algunas implicaciones relacionadas con la educación y la evaluación de ciertos elementos curriculares y transversales importantes en la formación de todo sujeto. Por ejemplo, la importancia de la amistad y la interacción social, la meditación, el respeto a la naturaleza, el amor familiar y, sobre todo, el valor del diálogo y el respeto a las minorías. Que no se olvide que las insinuaciones y las implicaciones discursivas son presuposiciones o silencios que siempre pueden expresarse mediante actos de habla directos, esto en caso de que el sujeto tenga las competencias y cuente con un contexto adecuado. En suma, enumero y condenso las conclusiones:

1. La memoria es la unidad sémica que permite la construcción del sujeto en la narrativa de Veloz Maggiolo, pero además funciona como vinculación primaria del sujeto con el contexto social.

2. Las fuentes de conocimiento de un sujeto se manifiestan a través de la memoria textual o semántica.

3. La memoria representa una categoría radial, por tanto, debe ser analizada desde el análisis del discurso narrativo de cualquier narrativa y de cualquier época.

4. La memoria es un registro de vivencias y recuerdos, pero también de conocimiento y predicciones simbólicas y semióticas.

5. La memoria tiene una función onírica, social, textual e intertextual.

5. Podría pensarse que la memoria en Veloz Maggiolo es un recurso vanguardista a lo Joyce o Proust, pero no lo es, porque su manifestación obedece a un sentimiento más atávico y así se constituye en fundamento mítico de su narrativa (esto vale también para sus novelas). 
6. La memoria histórica pesa tanto como la personal o la social.

7. La memoria es la base de la identidad narrativa de todo sujeto que existe y que habla.

\section{Referencias}

Bal, M. (1995). Teoría de la narrativa: una introducción a la narratología. (Trad. de Javier Franco). Madrid: Cátedra.

Benveniste, E. (1989). Problemas de lingüistica general (T. I y II). México: Siglo XXI.

Bruni, N. (2002). El trujillismo en Uña y carne de Marcio Veloz Maggiolo. Revista Mexicana del Caribe, 7(13), 153-179. Recuperado de http:// www.redalyc.org/pdf/128/12801306.pdf

Chomsky, N. (2007). Estructuras sintácticas. México: Siglo xxI.

Deleuze, G. (2005). Lógica del sentido. (Trad. de Miguel Morey). Barcelona: Paidós.

Eco, U. (2002). Sobre literatura. (Trad. De Helena Lozano Miralles). Barcelona: RqueR.

Greimas, A. J. (1971). Semántica estructural. (Versión espańola de Alfredo de la Fuente). Madrid: Gredos.

Matos Moquete, M. (1999). La cultura de la lengua. Santo Domingo: INTEC.

Matos Moquete, M. (2016). Discurso y acción: Manolo, Caamaño y El Moreno, Santo Domingo (en fase de edición).

Meschonnic, H. (2015). Spinoza, poema del pensamiento. (Trad. de Hugo Sabino). Buenos Aires: Cactus.

Mukařovský, J. (1977). Escritos de estética y semiótica. Barcelona: Editorial Gustavo Gili.
Navarro, D. (2004). Intertextualität: La teoría de la intertextualidad en Alemania. La Habana: Casa de las Américas/UNEAC.

Peña Abril, L. (1997). Análisis del discurso: hacia una semiótica de la interacción textual. Barcelona: Cátedra.

Rama, A. (1984). La ciudad letrada. Hanover: Ediciones del Norte.

Ricoeur, P. (2003). La memoria, la historia, el olvido. (Trad. de Agustín Neira). Madrid: Editorial Trotta.

Roa Ogando, G. (2016). La taxonomía del discurso: aspectos de la teoría lingüística. Santo Domingo: el autor.

Rodríguez-Henríquez, R. (2010). Fuentes de la imaginación histórica en la narrativa de Marcio Veloz Maggiolo. New York: Edwin Mellen Press.

Rodríguez, I. \& Martínez, J. (Eds.) (2012). Literaturas latinoamericanas: historia y crítica. Iberoamericana, 12(46), 2-21. Recuperado de https://journals.iai.spk-berlin.de/index.php/ iberoamericana/article/viewFile/1221/877

Woldak, R. \& Meyer, M. (2003). Método de análisis crítico del discurso. (Trad. de Tomás Fernández y Beatriz Eguibar). Barcelona: Gedisa.

Valerio-Holguín, F. (Ed.) (2000). Arqueología de las sombras: la narrativa de Marcio Veloz Maggiolo. Santo Domingo: Amigo del Hogar.

Van Dijk, T. (1983). La ciencia del texto: un enfoque interdisciplinario. Barcelona: Paidós.

Van Dijk, T. (1999). El análisis crítico del discurso. Recuperado de http://www.discursos.org/oldarticles/El\%20an \%E1lisis\%20cr\%EDtico\%20 del\%20discurso.pdf

Veloz Maggiolo, M. (1982). La fértil agonía del amor. Santo Domingo: Taller. 
Veloz Maggiolo, M. (1986). Cuentos, recuentos y casicuentos. Santo Domingo: Taller.

Veloz Maggiolo, M. (2000). Cuentos para otros milenios. Santo Domingo: Editora Cole.

Veloz Maggiolo, M. (2006). Palabras de ida y vuelta. Santo Domingo: Editora Cole.

\section{Datos de filiación}

Fari Rosario. Es candidato a doctor en Estudios del Español: Lingüística y Literatura por la Pontificia Universidad Católica Madre y Maestra (PUCMM); maestría en Lingüística Aplicada a la Enseñanza del Espańol por Universidad Autónoma de Santo Domingo (UASD); licenciatura en Filosofía por la Pontificia Universidad Católica Madre y Maestra (PUCMM).

Líneas de investigación:

La narrativa caribeńa y lo real maravilloso en Veloz Maggiolo y Carpentier

La metáfora y sus alcances lingüísticos y científicos

Correo electrónico: ramón.rosario@intec.edu.do 